
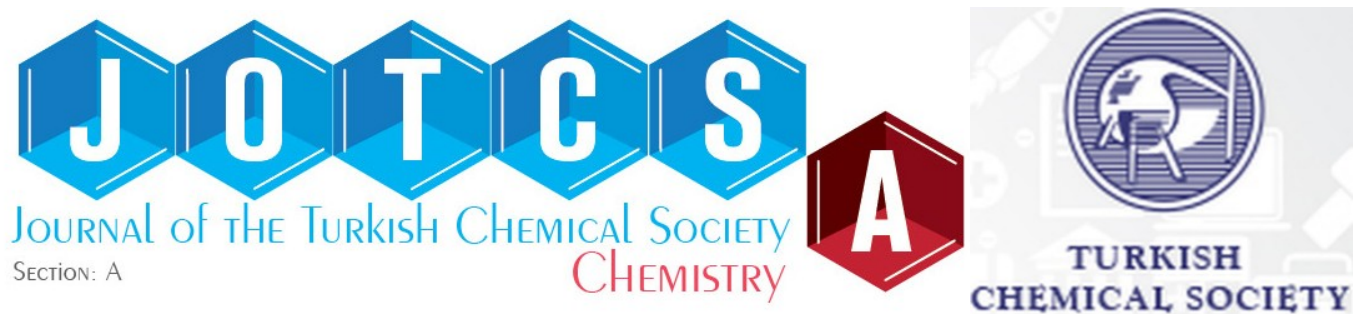

\title{
Actinobacteria Isolation from Forest Soils and Determination of Biological Activities
}

\author{
Pervin Soyer $^{1}\left[D\right.$, Yağmur Tunalı $^{1 *} \square[D$
}

${ }^{1}$ Anadolu University, Faculty of Pharmacy, Department of Pharmaceutical Microbiology, 26470, Eskişehir, Turkey.

\begin{abstract}
Actinobacteria bacterial group has one of the most populous population in microorganisms that extends very different and extensive habitats on earth especially the main character of the natural soil habitats. Since old times, bioactive metabolites of soil microorganisms have been studied and the results have provided that metabolites of these microorganisms have significant benefits to science, medicine, agriculture, and the pharmaceutical industry. In this study, isolation of Actinobacteria strains from forest soils, identification of morphological and molecular features, extraction of the bioactive metabolite of isolates and determination the antimicrobial, antibiofilm, and cytotoxic activities of bioactive extract were tested. The microbiological isolation methods for collected forest soil samples were used and after the determination of their morphological and molecular features, isolates were defined as Brevibacterium spp. that is a member of Actinobacteria. The antibiotic resistance of the isolates was determined by different methods and different concentrations of standard antibiotics. The chromium tolerance of isolates was also determined. The bioactive metabolites of isolates were produced in a modified medium and extracted. The antimicrobial, antibiofilm, cytotoxic activities of bioactive metabolites were determined against standard microorganisms and Artemia salina larvae were used as a test organism for cytotoxic tests. In the present study, results provided information about Actinobacteria that were isolated from forest soils. Isolates have antibiotic resistance and chromium tolerance abilities. Moreover, it has been shown that the Actinobacteria group is the largest bioactive metabolite producing group in terms of both antibacterial and antifungal activity and also contains a wide range of other compounds such as antibiofilm and cytotoxic compounds. The antimicrobial (MIC) concentrations of bioactive metabolites were detected $2500 \mu \mathrm{g} / \mathrm{mL}$ for standard bacteria cultures and $1250 \mu \mathrm{g} / \mathrm{mL}$ for yeasts. The antibiofilm (MBEC) value was determined at $1250 \mu \mathrm{g} / \mathrm{mL}$. The $2500 \mu \mathrm{g} / \mathrm{mL}$ concentration of the extract was found to be the effective cytotoxic value. The results provide Brevibacterium spp. isolates have industrial and pharmaceutical potential and more detailed pharmaceutical researches are planned.
\end{abstract}

Keywords: Actinobacteria, Brevibacterium, antibacterial, antifungal

Submitted: December 09, 2019. Accepted: February 21, 2020.

Cite this: Soyer P, Tunalı Y. Actinobacteria Isolation from Forest Soils and Determination of Biological Activities. JOTCSA. 2020;7(2):327-34.

DOI: https://doi.org/10.18596/jotcsa.657180.

*Corresponding author. E-mail: yagmurt@anadolu.edu.tr Tel: 05325546003.

\section{INTRODUCTION}

Soil is a highly complex, heterogeneous, and nutrient-limited environment consisting of an organic matrix with liquid and gaseous pores possessing the highest microbial diversity on the Earth (1). Molecular phylogenetic analyses reveal that the soil and rhizosphere can contain thousands of unique bacterial species per gram (2). The phylum of Actinobacteria is well-known for its ability to produce a wealth of natural products with structural complexity and with diverse biological activities (3). Actinobacteria bacterial group has one of the most populous populations of microorganisms that extend very different and extensive habitats on earth. Actinobacteria and its members are the main 
characteristics of natural soil habitats. Especially, forest soils are eligible habitats for soil microorganisms, it contents organic-inorganic materials, various organisms, and their wastes. Actinobacteria are Gram-positive, free-living, saprophytic bacteria, widely distributed in soil, water, and colonizing plants with a filamentous structure.

Bacteria produce a vast array of secondary metabolites, which have diverse and important ecological functions. It has become increasingly clear that secondary metabolite production often is triggered by intra- and inter-specific interactions between soil bacteria. Soil bacteria produce a large number of secondary metabolites that have many different physicochemical and biological properties (1). Bioactive metabolites of microorganisms especially soil microorganisms have studied for many years and the results have provided that metabolites of soil microorganisms have significant benefits to science, medicine, agriculture, and the pharmaceutical industry. Actinobacteria have also ability to synthesize antiviral (4), antibacterial, antifungal (5), antibiofilm, antitumoral (6), insecticidal (7), antioxidative (8), anti-inflammatory (9), anti-biofouling (10), immunosuppressive (11), anti-parasitic (7), plant-growth-promoting and herbicidal compounds (12), enzyme inhibitors (6) and industrially important enzymes. From the 22,500 biologically active compounds that have been obtained from microbes, $45 \%$ are produced by Actinobacteria, $38 \%$ by fungi, and $17 \%$ by unicellular bacteria (13).

The main focus of this study was to isolate, characterize and identification of Actinobacteria strains that were collected from forest soils in the Çanakkale-Gelibolu region in Turkey. The isolated Actinobacteria strain was growth in special media and extracted to obtain the bioactive metabolite in crude extract form. The collected crude extract was evaluated with its antibacterial, antifungal, antibiofilm, and cytotoxic features.

\section{EXPERIMENTAL SECTION}

\section{Isolation and characterization}

The soil samples were collected from 6 to $10 \mathrm{~cm}$ depth from forest regions in Çanakkale-Gelibolu, Turkey. For sampling, moist and fertile soils that are rich in organic matter were selected.

After collection, soil samples were serially diluted up to $10^{-5}$ and inoculated to special isolation modified media. The content of this medium was as follows: Dextrose $(4 \mathrm{~g} / \mathrm{L})$, yeast extract $(4 \mathrm{~g} / \mathrm{L})$, malt extract $(10 \mathrm{~g} / \mathrm{L}), \mathrm{CaCO}_{3}$ (calcium carbonate) $(2 \mathrm{~g} / \mathrm{L}$ ) and agar $(4 \mathrm{~g} / \mathrm{L})$. The cultures were incubated at $37^{\circ} \mathrm{C}$ for 3-5 days (14). This culture-dependent isolation method was continued until the pure colonies shown on the agar surface typically resemble Actinobacteria. The morphological characterization of these colonies determined by using the Gram staining method.

\section{Molecular identification}

The selected pure cultures were identified by using their 16S rRNA (ribosomal RNA) sequence. After, DNA isolation PCR (Polymerase Chain Reaction) amplification methods were used. The 27F/1492R universal primers were used and 1450 base pairs of $16 \mathrm{~S}$ rRNA were amplified by using PCR. Two primers 27F (5'-AGAGTITGATCMTGGCTCAG-3') and 1492R (5'-TACGGYTACCTTGTTACGACTT-3') were used. Sequencing was performed by using the EURX Gene Matrix Bacterial Genomic DNA Purification Kit. The PCR protocol used was as follows: $95{ }^{\circ} \mathrm{C}$ for 5 minutes, $56{ }^{\circ} \mathrm{C}$ for 40 seconds, $72{ }^{\circ} \mathrm{C}$ for 60 seconds, 35 cycles of denaturation at $95^{\circ} \mathrm{C}$ for 40 seconds, annealing at $56^{\circ} \mathrm{C}$ for 40 seconds, and elongation at $72{ }^{\circ} \mathrm{C}$ for 45 seconds. Amplification was followed by a final extension at $72{ }^{\circ} \mathrm{C}$ for 5 minutes. After the PCR reaction was completed, 10 $\mu \mathrm{L}$ of the obtained PCR product was electrophoresed on a $1 \% 1 \times$ Tris-acetate-EDTA agarose gel containing ethidium bromide. PCR products were produced for bidirectional sequence analysis by mixing with their respective forward and reverse primers. The analyses were carried out in duplicate with the Sanger sequencing device and the Big Dye Terminator $v 3.1$ Cycle Sequencing Kit (Applied Biosystems). The $16 \mathrm{~S}$ rRNA gene sequence was compared to a sequence in the public database using basic local alignment search tool (BLAST Basic Local Alignment Search Tool) on the national center for biotechnology information (NCBI (National Center for Biotechnology Information)) website (www.ncbi.nlm.nih.gov). The homology of the 16S rRNA sequence of the isolate was analyzed by using BLAST software $(15,16)$.

\section{Determination of the antimicrobial resistance of isolates}

Antibiotic resistance was determined by the disc diffusion method. The antibiotic resistance of Actinobacteria culture were determined both by disc diffusion and microbroth dilution methods against standard antibiotic discs; AmC-30 (amoxicilin+clavulanic Acid 30/10 $\mu \mathrm{g}$ ), SAM-20 (ampicillin+sulbactam 10/10 $\mu \mathrm{g}$ ), IPM-10 (imipenem $10 \mu \mathrm{g}$ ) B (bacitracin $0.004 \mu \mathrm{g}$ ), OFX-10 (ofloxacin $10 \mu \mathrm{g}$ ) and TEC-30 (teicoplanin $30 \mu \mathrm{g}$ ). $100 \mu \mathrm{L}$ of Actinobacteria culture inoculated to MHA (Mueller Hinton Agar) and the standard antibiotic discs were put on the agar and incubated at $37^{\circ} \mathrm{C}$, for 24 hours. After the incubation period, the inhibition zones around the discs were measured (17). The microbroth dilution method (minimum inhibitory concentration - MIC) was defined as the lowest concentrations necessary for the inhibition of growth. 6 different concentrations (156.25, 78.125, $39.062,19.53,9.75$, and $4.87 \mu \mathrm{g} / \mathrm{mL}$ ) of standard antibiotics chloramphenicol, amoxicillin and ampicillin were used. Overnight microorganism culture was adjusted to McFarland's 0.5 standard. $100 \mu \mathrm{L}$ of each antibiotic concentrations and $100 \mu \mathrm{L}$ 
of microorganism cultures were inoculated to the well plates and incubated at $37^{\circ} \mathrm{C}$, for 24 hours. After the incubation period, the wells were stained by $20 \mu \mathrm{L}$ resazurin dye to observe the color difference between dead and living cells.

\section{Screening of the chromium tolerance}

Potassium chromate $\left(\mathrm{K}_{2} \mathrm{CrO}_{4}\right)$ and chromium(III) chloride $\left(\mathrm{CrCl}_{3}\right)$ salts were used at $100,75,50,25$, and $12.5 \mathrm{mg} / 100 \mathrm{~mL}$ concentrations. The chromium powders were added to PYE (peptone, yeast extract) and MHA (Mueller Hinton Agar) at proper concentrations by using the agar dilution method (18). The $50 \mu \mathrm{L}$ of Actinobacteria culture was inoculated to the medium and incubated at $37^{\circ} \mathrm{C}, 96$ hours. Microbroth dilution method was also used at $25,12.56 .25,3.125$, and $1.562 \mathrm{mg} / 100 \mathrm{~mL}$ concentrations. $100 \mu \mathrm{L}$ of $\mathrm{K}_{2} \mathrm{CrO}_{4}$ and $\mathrm{CrCl}_{3}$ was added to Brevibacterium sp. that adjusted to McFarland 0.5 and incubated at $37^{\circ} \mathrm{C}$, for 24 hours. Following the incubation period, a $150 \mu \mathrm{L}$ aliquot was taken from each concentration wells and inoculated to $\mathrm{MHA}$ and incubated at $37^{\circ} \mathrm{C}, 96$ hours. After the incubation, colonies on the plate were counted.

\section{Fermentation and extraction of bioactive} metabolites from Brevibacterium

For the fermentation step, a submerged culture method was used. The pure Brevibacterium spp. isolate was grown in the modified medium containing; $4 \mathrm{~g} / \mathrm{L}$ of glucose, $10 \mathrm{~g} / \mathrm{L}$ of malt extract, $4 \mathrm{~g} / \mathrm{L}$ of yeast extract, $1 \mathrm{~g} / \mathrm{L}$ of $\mathrm{K}_{2} \mathrm{HPO}_{4}$ (potassium hydrogen phosphate), $\mathrm{MgSO}_{4}$ (magnesium sulfate), $\mathrm{NaCl}$ (sodium chloride), $0.001 \mathrm{~g} / \mathrm{L}$ of $\mathrm{FeSO}_{4}$ (iron(II) sulfate) and $2 \mathrm{~g} / \mathrm{L}$ of $\mathrm{CaCO}_{3}$ (calcium carbonate). The prepared cultures were incubated $37^{\circ} \mathrm{C}$, for 7 days. After the incubation period, organic solvent extraction was performed. The broth was filtered through a Whatman No.1 filter and cultures were extracted three times with equal volume of ethyl acetate (EtOAc) at a 1:1 ratio. Then the EtOAc solution was evaporated for dryness by using a rotary evaporator at $30^{\circ} \mathrm{C}, 80 \mathrm{rpm}$, under $187 \mathrm{mbar}$ vacuum and the crude extract was collected (19).

\section{Determination of minimum inhibitory concentration (MIC) of bioactive metabolite}

5 different concentrations crude extract were applied to Escherichia coli ATCC 35218, Staphylococcus aureus ATCC 29213, Klebsiella pneumoniae ATCC 700603, Bacillus subtilis NRRL B478, Staphylococcus epidermidis ATCC 14990, Streptococcus pyogenes ATCC 13615, Listeria monocytogenes ATCC 19111 and Candida albicans ATCC 90028 species by using 96 well plate assay. Brevibacterium crude extract was weighed and dissolved in \%5 DMSO. Proper concentrations were
2500, 1250, 625, 312, and $156 \mu \mathrm{g} / \mathrm{mL}$. Overnight microorganism cultures were adjusted to McFarland 0.5 standard. $100 \mu \mathrm{L}$ of each extract concentrations and $100 \mu \mathrm{L}$ of each microorganism cultures were inoculated to the well plates and incubated at $37^{\circ} \mathrm{C}$, for 24 hours. \%5 DMSO, ketoconazole for fungi and chloramphenicol for bacteria species were also used as a control with $100,50,25,12.5,6.25,3.125$, $1.562,0.781,0.390$, and $0.195 \mu \mathrm{g} / \mathrm{mL}$ values. After incubation period wells were stained by $20 \mu \mathrm{L}$ resazurin dye to observe the color difference between dead and living cells $(20,21)$.

\section{Biofilm eradication assay of bioactive metabolite}

Microbial biofilms are communities of microorganisms embedded in a self-producing matrix, forming on living and nonliving surfaces. The inhibition effect of crude extract on biofilm formation was evaluated in 96-well plates. Briefly, overnight Staphylococcus aureus ATCC 29213, Staphylococcus epidermidis ATCC 14990, Candida albicans ATCC 90028 cultures were adjusted to McFarland 0.5 standard. $200 \mu \mathrm{L}$ of each bacteria were inoculated to the well plates and incubated at $37^{\circ} \mathrm{C}$, for 48 hours to form the biofilm at the bottom of the wells. After the incubation period, wells were gently washed twice with $100 \mu \mathrm{L}$ of $0.9 \%$ $\mathrm{NaCl}$ (physiological saline). $100 \mu \mathrm{L}$ of concentrations $(1250,625,312,156$, and $78 \mu \mathrm{g} / \mathrm{mL})$ of crude extract were added to each well and incubated at $37^{\circ} \mathrm{C}, 24$ hours. After the incubation period, wells were stained by $20 \mu \mathrm{L}$ resazurin dye. $(22,23,24)$

\section{Brine shrimp lethality test of bioactive metabolite}

A 24-h LC LC $_{50}$ (lethal concentration) bioassay was performed in a 96 well plate using nauplii of the Brine shrimp Artemia salina (25). Commercially sold Artemia mix was used. $18 \mathrm{~g}$ of the Artemia mix was poured to the $500 \mathrm{~mL}$ of distilled water and incubated $48-52$ hours at $30{ }^{\circ} \mathrm{C}$. After larvae had been seen, they were taken and counted. Brine shrimp lethality bioassay was determined with crude extract concentrations; 2500, 1250, 625, 312, and $156 \mu \mathrm{g} / \mathrm{mL}$ with 10 Artemia salina larvae in each concentration wells. After 24 hours incubation period, the alive larvae were counted.

\section{RESULTS AND DISCUSSION}

\section{Isolation, characterization and molecular identification of Actinobacteria}

In the present study, 25 Actinobacteria strains were isolated from collected soil samples. The Gram staining method was applied to all of these isolates. Some of them are shown in Figures below 1. a, b, c. 


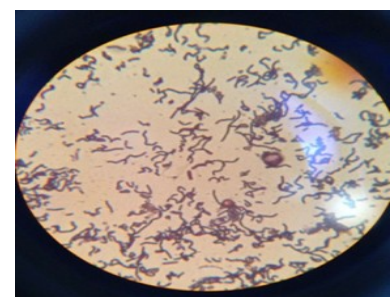

Figure 1.a

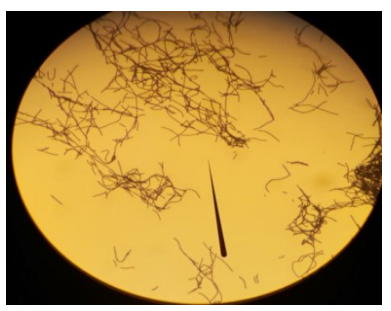

Figure 1.b

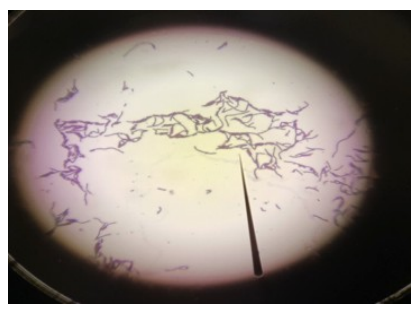

Figure 1.c.

Actinobacteria isolates after the Gram staining method.

The selected pure cultures were identified by using their 16S rRNA sequence. The results showed that most of them identified as Brevibacterium spp. BLAST analysis of the isolate showed that it is $100 \%$ similar to Brevibacterium spp. called Brevibacterium frigoritolerans (Accession Numbers: MN062932.1 and MN845150.1) which are the many Brevibacterium species available in the Gen Bank. Brevibacterium is one of the soil microbial communities that uncommon members of the Actinobacteria class. Brevibacterium is a member of the Actinobacteria phylum and genus of the Brevibacteriaceae family that is aerobic, nonsporulating, Gram-positive rod to coccoid shape and grows in a saline environment.

\section{Determination of the antibiotic resistance of isolates}

The antibiotic resistance of these isolates was determined by using standard antibiotic discs; AmC30 (amoxicilin+clavulanic acid 30/10 $\mu \mathrm{g}$ ), SAM-20 (ampicillin+sulbactam 10/10 $\mu \mathrm{g}$ ), IPM-10 (imipenem $10 \mu \mathrm{g}$ ), B (bacitracin $0.004 \mu \mathrm{g}$ ), OFX-10 (ofloxacin $10 \mu \mathrm{g}$ ) and TEC-30 (teicoplanin $30 \mu \mathrm{g}$ ). It showed the most sensible reaction to IPM-10 (imipenem 10 $\mu \mathrm{g})$. Also, the other values are shown in Table 1. Additionally, the MIC values are $78.125 \mu \mathrm{g} / \mathrm{mL}$ for chloramphenicol and $4.87 \mu \mathrm{g} / \mathrm{mL}$ for amoxicillin and ampicillin.

Table 1. Antibiotic resistance results from the disc diffusion method in terms of millimeters ( $\mathrm{mm})$.

\begin{tabular}{ll}
\hline $\begin{array}{l}\text { Standard } \\
\text { Antibiotic } \\
\text { Discs }\end{array}$ & $\begin{array}{l}\text { Brevibacterium } \\
\text { spp. } \\
\text { zone } \\
\text { inmibition } \\
\text { diameters }\end{array}$ \\
\hline AmC-30 & 19 \\
SAM-20 & 16 \\
IPM-10 & 20 \\
TEC-30 & 8 \\
OFX-10 & 12 \\
B-0.04 & 0 \\
\hline
\end{tabular}

\section{Screening of the chromium tolerance}

While 150-160 colonies were counted in chromium(III) chloride $\left(\mathrm{CrCl}_{3}\right)$ plate at $50 \mathrm{mg} / 100$ $\mathrm{mL}$ concentration, $25 \mathrm{mg} / 100 \mathrm{~mL}$ concentration plate formed 200-300 colonies. In $50 \mathrm{mg} / 100 \mathrm{~mL}$ potassium chromate $\left(\mathrm{K}_{2} \mathrm{CrO}_{4}\right)$ plate $50-100$ colonies and in $25 \mathrm{mg} / 100 \mathrm{~mL}$ plate $100-150$ colonies were counted. Additionally, at the results of microbroth dilution for chromium(III) chloride $\left(\mathrm{CrCl}_{3}\right)$ and potassium chromate $\left(\mathrm{K}_{2} \mathrm{CrO}_{4}\right)$, there was no formation of colonies. The test will be repeated using different concentrations. Chromium is one of the poisonous polluting metal ions that is found in soils. Several studies have demonstrated
Brevibacterium spp. has chromium tolerance and chromium degradation abilities. Hence, chromium tolerance of isolates was tested by the agar dilution method. It showed significant tolerance to potassium chromate $\left(\mathrm{K}_{2} \mathrm{CrO}_{4}\right)$ and chromium(III) chloride $\left(\mathrm{CrCl}_{3}\right)$ salts.

\section{Determination of minimum inhibitory} concentration (MIC) of bioactive metabolite

The MIC value of bioactive metabolite extract was tested at 2500, 1250, 625, 312, $156 \mu \mathrm{g} / \mathrm{mL}$ concentrations. The results are shown in Tables 2 and 3. The yeast species are more sensitive than bacteria species. 
Table 2. MIC values of metabolite and chloramphenicol against bacteria species.

\begin{tabular}{|c|c|c|}
\hline \multirow[b]{2}{*}{ Microorganisms } & \multicolumn{2}{|c|}{ MIC Values ( $\mu \mathrm{g} / \mathrm{mL})$} \\
\hline & Bioactive Metabolites & Chloramphenicol \\
\hline Escherichia coli ATCC 35218 & 2500 & 78.125 \\
\hline Staphylococcus aureus ATCC29213 & 2500 & 4.882 \\
\hline Listeria monocytogenes ATCC 19111 & 2500 & 9.765 \\
\hline Klebsiella pneumonia ATCC 700603 & 2500 & 19.531 \\
\hline Bacillus subtilis NRRL B478 & 2500 & 2.441 \\
\hline $\begin{array}{l}\text { Staphylococcus epidermidis ATCC } \\
14990\end{array}$ & 2500 & 9.765 \\
\hline Streptococcus pyogenes ATCC 13615 & 2500 & 39.0625 \\
\hline
\end{tabular}

Table 3. MIC values of metabolites and ketoconazole against yeast species.

\begin{tabular}{lll}
\hline & \multicolumn{2}{c}{ MIC Values ( $\mathbf{\mu g} / \mathbf{m L} \mathbf{)}$} \\
Microorganisms & Bioactive Metabolites & Ketoconazole \\
\hline Candida albicans ATCC 90028 & 1250 & 19.531 \\
Candida krusei ATCC 6258 & 1250 & 39.0925 \\
\hline
\end{tabular}

Several studies have demonstrated that secondary metabolites produced by soil bacteria can serve as weapons in microbial warfare, providing an advantage to producer strains when competing against other microbial competitors in the same ecological niche (26).

\section{Biofilm eradication assay of bioactive metabolite}

Antibiofilm studies demonstrated a dose-dependent activity. The antibiofilm activity of bioactive metabolite extract was examined by minimum biofilm eradication concentration (MBEC) assay. The antibiofilm value of bioactive metabolite extract was determined $1250 \mu \mathrm{g} / \mathrm{mL}$ for Staphylococcus aureus, $1250 \mu \mathrm{g} / \mathrm{mL}$ for Staphylococcus epidermidis and
$1250 \mu \mathrm{g} / \mathrm{mL}$ for Candida albicans. It means, the extract showed the same efficiency to selected microorganisms and eradicate their biofilm structure at the same dose. $1250 \mu \mathrm{g} / \mathrm{mL}$ of bioactive metabolite extract is a proper concentration for eradicating the biofilm formation of tested microorganisms.

\section{Brine shrimp lethality test of bioactive metabolite}

The brine shrimp lethality test was determined at 2500, 1250, 625, 312, and $156 \mu \mathrm{g} / \mathrm{mL}$ concentrations. The lethality values of Artemia salina larvae are shown in Table 4. 2500 and 1250 $\mu \mathrm{g} / \mathrm{mL}$ concentrations are the most effective doses on larvae. The larvae are counted out of 10 larvae.

Table 4. Results of the Brine shrimp lethality test.

\begin{tabular}{lll}
\hline $\begin{array}{l}\text { Bioactive } \\
\text { Concentrations }(\boldsymbol{\mu g} / \mathbf{m L})\end{array}$ & $\begin{array}{l}\text { Amount of Alive Artemia } \\
\text { salina Larvae (out of 10) }\end{array}$ & $\begin{array}{l}\text { Percentage (\%) Effect of } \\
\text { Bioactive Metabolite }\end{array}$ \\
\hline 2500 & 0 & $100 \%$ \\
1250 & 2 & $80 \%$ \\
625 & $3 \pm 1$ & $60-70 \%$ \\
312 & $3 \pm 1$ & $60-70 \%$ \\
156 & $4 \pm 1$ & $50-60 \%$ \\
\hline
\end{tabular}

The cytotoxic efficacy of the bioactive metabolite extract is significantly observed at different concentrations. It can be used as an anticancer drug in cell culture studies. The studies will be continued to understand all of the efficacy mechanisms with different tests.

\section{CONCLUSION}

The search for novel microorganism species from soils has gained momentum in recent years. Nature acts as a prominent reservoir for isolating the microorganisms that have various biological activities. The results from in vitro experiments, a Brevibacterium spp. called Brevibacterium frigoritolerans was isolated. In this study, many biological activities of this isolate have been tested and proved. The isolated novel bacterial strain was characterized by morphological, molecular, antimicrobial resistance, and chromium tolerance features and activities. For the determination of Brevibacterium spp. isolates antibiotic resistance, AmC-30 (amoxicilin+clavulanic acid 30/10 $\mu \mathrm{g}$ ), SAM-20 (ampicillin+sulbactam 10/10 $\mu \mathrm{g}$ ), IPM-10 (imipenem $10 \mu \mathrm{g}$ ), B (bacitracin $0.004 \mu \mathrm{g}$ ), OFX-10 (ofloxacin $10 \mu \mathrm{g}$ ) and TEC-30 (teicoplanin $30 \mu \mathrm{g}$ ) standard antibiotic discs were used. IPM-10 (imipenem $10 \mu \mathrm{g}$ ) was the most effective and B (bacitracin $0.004 \mu \mathrm{g}$ ) is not effective at all. Chromium is a heavy metal and causes environmental pollution. It accumulates in soil and is a very carcinogenic substance. For this reason, the chromium tolerance of Brevibacterium spp. isolates were determined. Das and Mishra showed that Brevibacterium spp. tolerates to potassium chromate $\left(\mathrm{K}_{2} \mathrm{CrO}_{4}\right)$ (27). This research proved that 
Brevibacterium spp. isolates tolerate both potassium chromate $\left(\mathrm{K}_{2} \mathrm{CrO}_{4}\right)$ and chromium(III) chloride $\left(\mathrm{CrCl}_{3}\right)$ salts. The crude extract was checked for antibacterial, antibiofilm, and cytotoxic activities to identify the mechanisms of bioactive metabolite. Brevibacterium spp. showed different bioactive features, which highlighted its importance as potential pharmacological agents. Hence, there could be a probability of a new bioactive compound in the crude extract, which might provide a basis for further development of novel compounds from Brevibacterium spp. In Oskay's research, bioactive metabolites of Actinobacteria showed antimicrobial activities against Staphylococcus aureus, Escherichia coli and Candida albicans microorganisms (28). In the present study, bioactive metabolites of Brevibacterium spp. isolates that member of Actinobacteria showed antimicrobial activity against Staphylococcus aureus ATCC29213, Escherichia coli ATCC 35218, Klebsiella pneumonia ATCC 700603, Bacillus subtilis NRRL B478, Staphylococcus epidermidis ATCC 14990, Streptococcus pyogenes ATCC 13615 Listeria monocytogenes ATCC 19111, Candida albicans ATCC 90028, Candida krusei ATCC 6258 and antibiofilm activity against Staphylococcus aureus ATCC29213, Staphylococcus epidermidis ATCC 14990, Candida albicans ATCC 90028 at different concentrations of the crude extract. It has been previously shown that bioactive metabolites of Actinobacteria at $0.1-10 \mu \mathrm{g} / \mathrm{mL}$ concentrations showed a $100 \%$ cytotoxic activity on Artemia salina larvae (29). In the current study, $80-100 \%$ cytotoxic activities at 2500 and $1250 \mu \mathrm{g} / \mathrm{mL}$ concentrations were determined. There are limited data in the literature about the activities of Brevibacterium bioactive metabolites. This research also provided new insight into the development of good candidates for pharmaceutical and bioactive natural products. The development of new drugs can be a candidate for curing several types of diseases (30). The current attempt of using Brevibacterium isolates and its bioactive metabolites will be favorable for antimicrobial, antitumoral, antibiofilm and cytotoxic activity tests.

\section{REFERENCES}

1. Tyc O, Song C, Dickschat JS, Vos M, Garbeva P. The Ecological Role of Volatile and Soluble Secondary Metabolites Produced by Soil Bacteria. Trend Microb. 2017;25(4):280-92.

2. Uroz $S$, Buée $M$, Murat $C$, Frey-Klett $P$, Martin $F$. Pyrosequencing reveals a contrasted bacterial diversity between oak rhizosphere and surrounding soil. Environ Microbiol. 2010; 2:281-8.

3. Adegboye MF, Babalola O. Taxonomy and ecology of antibiotic producing Actinomycetes. Afr J Agric Res. 2012; 15:2255-61.
4. Sacramento DR, Coelho RRR, Wigg MD, Linhares LFTL, Santos MGM, Semedo LTAS. Antimicrobial and antiviral activities of an actinomycete (Streptomyces sp.) isolated from a Brazilian tropical forest soil. World J Microbiol Biotechnol. 2004; 20:225-9.

5. Zarandi ME, Bonjar GHS, Dehkaei FP, Moosavi SAA, Farokhi PR, Aghighi S. Biological control of rice blast (Magnaporthe oryzae) by use of Streptomyces sindeneusis isolate 263 in greenhouse. Am J Appl Sci. 2009;6:194-9.

6. Hong K. Gao AH, Xie QY, Gao H, Zhuang L, Lin HP. Actinomycetes for marine drug discovery isolated from mangrove soils and plants in China. Mar Drugs. 2009;7: 24-44.

7. Pimentel-Elardo SM, Kozytskam S, Bugni TS, Ireland CM, Moll $\mathrm{H}$, Hentschel $U$. Antiparasitic compounds from Streptomyces sp. strains isolated from Mediterranean sponges. Mar Drug. 2010;8: 373-80.

8. Janardhan A, Kumar AP, Viswanath B, Saigopal DVR, Narasimha G. Production of bioactive compounds by Actinomycetes and their antioxidant properties. Biotechnol Res Int. 2014; 217030:1-9.

9. Renner $M K$, Shen $Y C$, Cheng $X C$, Jensen $P R$, Frankmoelle W, Kauffman CA. Cyclomarins A-C, new anti-inflammatory cyclic peptides produced by a marine bacterium (Streptomyces sp.). J Am Chem Soc. $1999 ; 121: 11273-6$.

10. Xu Y, He H, Schulz S, Liu X, Fusetani N, Xiong $\mathrm{H}$. Potent antifouling compounds produced by marine Streptomyces. Biores Technol. 2010; 101:1331-6.

11. Mann J. Natural products as immune suppressive agents. Nat Prod Rep. 2001; 18:41730.

12. Sousa CS, Soares ACF, Garrido MS. Characterization of Streptomycetes with potential to promote plant growth and biocontrol. Sci Agric. 2008;65:50-5.

13. Berdy J. Bioactive microbial metabolites: a personal view. J Antibiot. 2005; 58:1-26.

14. Yen $H$, Hsiao $H$, Chen $L$. The enhancement of rapamycin production using Streptomyces hygroscopicus through a simple $\mathrm{pH}$-shifted control. J Tai Ins Chem Engineers.2013;44:743-7.

15. Rintala $H A$, Nevalainen A, Rönkä MS. PCR primers targeting the 16S rRNA gene for the specific detection of Streptomycetes. Mol Cell Probes. 2001;15: 337-47. 
16. Singh V, Praveen F, Khan CKM. Tripathi, Phylogenetics of an antibiotic producing Streptomyces strain isolated from soil. Bioinformation. 2009;4: 53-8.

17. Clark CL, Jacobs MR, Appelbaum PC. Antipeumococcal Activities of Levofloxacin and Clarithromycin as Determined by Agar Dilution, Microdilution, ETest and Disk Diffusion Methodologies. J Clinical Microb.1998;36(12):357984.

18. Poornima K, Karthik L, Swadhini SP, Mythili S, Sathiavelu A. Degradation of Chromium by Using a Novel Strains of Pseudomonas Species. J Microb Biochem Technol. 2010;2: 95-9.

19. Zhao S, Huang D, Qi H, Wen J, Jia X. Comperative metabolic profiling-based improvement of rapamycin production by Streptomyces hygroscopicus. Appl Microb Biotech. 2013: 97;532941.

20. CLSI. Performance standards for antimicrobial susceptibility testing informational supplement M100-S19. 29th ed. 2009.

21. Anderws JM. Determination of minimum inhibitory concentrations. J of Antimic Chemot. 2001; 48:5-16.

22.Teanpaisan $R$, Kawsud $P$, Pahumunto $N$, Puripattanavong J. Screening for antibacterial and antibiofilm activity in Thai medicinal plant extracts against oral microorganisms. J Trad Compl Med. $2017 ; 7(2): 172-7$.

23. Cruz CD, Shah S, Tammela P. Defining conditions for biofilm inhibition and eradication assays for Gram-positive clinical reference strains.
BMC Microbiol. 2018;173:1-9.

24. Chaieb K, Kouidhi B, Jrah H, Mahdouani K, Bakhrouf A. Antibacterial activity of Thymoquinone, an active principle of Nigella sativa and its potency to prevent bacterial biofilm formation. BMC Complemen Alter Med. 2011;11: 29.

25. Meyer BN, Ferrigni NR, Putnam JE, Jacobsen LB, Nichols DE, Mclaughlin JL. Brine shrimp: a convenient general bioassay for active plant constituents. J Med PI Res. 1982;45;31-4.

26. Foster KR, Bell T. Competition, not cooperation, dominates interactions among culturable microbial species. Curr Biol. 2012; 22:1845-50.

27. Das A, Mishra S. Hexavalent chromium reduction and $16 S$ rDNA identification of bacteria isolated from a $\mathrm{Cr}$ (VI) contaminated site. Int J Microb. 2008:7;1.

28. Oskay M. A Research on Isolation, Taxonomy and Fermentation Studies of Streptomyces Strains with High Antimicrobial Activity from Northern Cyprus Soils [Master of Science Thesis]. [Manisa]; Celal Bayar University, Institute of Science; 2006.

29. Yavuz M. Isolation of Secondary Metabolites of Local Streptomyces Species, Illumination of Their Structures and Investigation of Their Biological Activities [Doctoral Thesis]. [Diyarbakır], Dicle University Institute of Science and Technology; 2010.

30. Padma BJ, Saraswathi K, Arumugam P, Shiny RA. Isolation, characterization and evaluation of antioxidant activities of secondary metabolites producing Actinomycetes of terrestrial origin. Int J of Res in Med Sci. 2018;6(3):1017-28. 
